\title{
Facial emotion processing in schizophrenia: a non-specific neuropsychological deficit?
}

\author{
E. Pomarol-Clotet ${ }^{1 *}$, F. Hynes ${ }^{2}$, C. Ashwin ${ }^{3}$, E. T. Bullmore ${ }^{4}$, P. J. McKenna ${ }^{1}$ and K. R. Laws ${ }^{5}$ \\ ${ }^{1}$ Benito Menni Complex Assistencial Salut Mental, Barcelona, and CIBERSAM, Spain \\ ${ }^{2}$ Birmingham and Solihull Mental Health Trust, Birmingham, UK \\ ${ }^{3}$ Department of Psychology, University of Bath, UK \\ ${ }^{4}$ Department of Psychiatry, University of Cambridge, Addenbrooke's Hospital, UK \\ ${ }^{5}$ School of Psychology, University of Hertfordshire, UK
}

Background. Identification of facial emotions has been found to be impaired in schizophrenia but there are uncertainties about the neuropsychological specificity of the finding.

Method. Twenty-two patients with schizophrenia and 20 healthy controls were given tests requiring identification of facial emotion, judgement of the intensity of emotional expressions without identification, familiar face recognition and the Benton Facial Recognition Test (BFRT). The schizophrenia patients were selected to be relatively intellectually preserved.

Results. The patients with schizophrenia showed no deficit in identifying facial emotion, although they were slower than the controls. They were, however, impaired on judging the intensity of emotional expression without identification. They showed impairment in recognizing familiar faces but not on the BFRT.

Conclusions. When steps are taken to reduce the effects of general intellectual impairment, there is no deficit in identifying facial emotions in schizophrenia. There may, however, be a deficit in judging emotional intensity. The impairment found in naming familiar faces is consistent with other evidence of semantic memory impairment in the disorder.

Received 9 March 2009; Revised 14 July 2009; Accepted 7 August 2009; First published online 24 September 2009

Key words : Cognition, emotion, face processing, schizophrenia.

\section{Introduction}

There has been a surge of interest recently in the finding of impaired ability to identify emotions from facial expressions in schizophrenia (Marwick \& Hall, 2008; Kohler et al. 2009). This deficit has been considered to be associated with aspects of the clinical picture such as positive and negative symptoms and social functioning (Mandal et al. 1998; Kohler et al. 2000; Silver et al. 2002; Sachs et al. 2004; Hofer et al. 2009). It has also been claimed to be a genetic vulnerability marker for the disorder (Bediou et al. 2007). Additionally, facial emotion tasks are being used increasingly as a tool for exploring the underlying neurobiology of schizophrenia in neuroimaging (Pinkham et al. 2003) and electrophysiological studies (Turetsky et al. 2007; Wynn et al. 2008).

\footnotetext{
* Address for correspondence: Dr E. Pomarol-Clotet, Benito Menni Complex Assistencial en Salut Mental, Germanes Hospitalàries del Sagrat Cor de Jesús, C/Doctor Antoni Pujades 38-C, 08830 Sant Boi de Llobregat, Barcelona, Spain.

(Email: edith.pomarol@gmail.com)
}

Although many studies have examined schizophrenia patients on tests requiring judgement of facial emotion and most have found evidence of impairment (Mandal et al. 1998; Edwards et al. 2002; Pinkham et al. 2003), often with a large effect size (Kohler et al. 2009), this does not in itself establish that facial emotion processing is an important area of deficit in the disorder. This is because patients with schizophrenia perform poorly on almost all cognitive tasks (Chapman \& Chapman, 1973), a finding that in turn almost certainly reflects the fact that the disorder is associated with a variable degree of general intellectual impairment (McKenna, 2007; Reichenberg \& Harvey, 2007). Indeed, there is an ongoing debate about whether the facial emotion recognition deficit in schizophrenia is specific, in the sense of being disproportionate to that seen in other areas of cognition, and several authors have argued that this has not been demonstrated conclusively (Archer et al. 1992; Kerr \& Neale, 1993; Johnston et al. 2001; Edwards et al. 2002).

A facial emotion processing deficit in schizophrenia could also be considered specific if it affected only 
Table 1. Studies examining the ability to identify specific emotions in patients with schizophrenia (studies are those published after the review of Edwards et al. 2002)

\begin{tabular}{|c|c|c|c|c|c|c|c|}
\hline \multirow[b]{2}{*}{ Study } & \multirow[b]{2}{*}{$n(\mathrm{scz} / \mathrm{con})$} & \multicolumn{6}{|c|}{ Emotion } \\
\hline & & Anger & Disgust & Fear & Happiness & Sadness & Surprise \\
\hline Gur et al. 2002 & $14 / 14$ & $\mathrm{~N}$ & $\mathrm{~N}$ & $\mathrm{~N}$ & $\mathrm{~N}$ & $\mathrm{~N}$ & \\
\hline Kohler et al. 2003 & $28 / 61$ & $\mathrm{~N}$ & Y & Y & $\mathrm{N}$ & $\mathrm{N}$ & \\
\hline Sachs et al. 2004 & $40 / 43$ & & & & $\mathrm{~N}$ & $\mathrm{~N}$ & \\
\hline Bediou et al. 2005a & $30 / 30$ & $\mathrm{Y}$ & $\mathrm{N}$ & $\mathrm{N}$ & $\mathrm{N}$ & $\mathrm{Y}$ & \\
\hline Bediou et al. 2005b & $29 / 20$ & & $\mathrm{Y}$ & $\mathrm{Y}$ & $\mathrm{N}$ & & \\
\hline Brune, $2005 a$ & $23 / 18$ & $\mathrm{Y}$ & $\mathrm{Y}$ & $\mathrm{Y}$ & $\mathrm{N}$ & $\mathrm{Y}$ & $\mathrm{Y}$ \\
\hline Kucharska-Pietura et al. 2005 & $100 / 50$ & Y & $\mathrm{Y}$ & Y & $\mathrm{Y}$ & & Y \\
\hline Bigelow et al. 2006 & $20 / 14$ & Y & $\mathrm{N}$ & Y & $\mathrm{Y}$ & $\mathrm{N}$ & $\mathrm{N}$ \\
\hline Chambon et al. 2006 & $20 / 18$ & $\mathrm{Y}$ & $\mathrm{Y}$ & $\mathrm{Y}$ & $\mathrm{Y}$ & Y & \\
\hline Schneider et al. 2006 & $20 / 20$ & $\mathrm{Y}$ & & $\mathrm{Y}$ & $\mathrm{Y}$ & $\mathrm{Y}$ & \\
\hline Bediou et al. 2007 & $40 / 26$ & $\mathrm{Y}$ & $\mathrm{Y}$ & $\mathrm{Y}$ & $\mathrm{Y}$ & & \\
\hline Namiki et al. 2007 & $20 / 20$ & $\mathrm{Y}$ & $\mathrm{Y}$ & $\mathrm{N}$ & $\mathrm{N}$ & $\mathrm{Y}$ & $\mathrm{Y}$ \\
\hline Van't Wout et al. 2007 & $37 / 41$ & $\mathrm{~N}$ & $\mathrm{~N}$ & $\mathrm{Y}$ & $\mathrm{N}$ & & \\
\hline Hall et al. 2008 & $24 / 24$ & $\mathrm{~N}$ & $\mathrm{~N}$ & Y & $\mathrm{N}$ & $\mathrm{N}$ & $\mathrm{N}$ \\
\hline Johnston et al. 2008 & $19 / 19$ & & & $\mathrm{Y}$ & & & Y \\
\hline Tsoi et al. 2008 & $25 / 25$ & & & $\mathrm{~N}$ & $\mathrm{Y}$ & $\mathrm{N}$ & \\
\hline Derntl et al. 2009 & $24 / 24$ & $\mathrm{Y}$ & $\mathrm{Y}$ & $\mathrm{Y}$ & $\mathrm{Y}$ & $\mathrm{Y}$ & \\
\hline Hofer et al. 2009 & $40 / 40$ & $\mathrm{~N}$ & $\mathrm{Y}$ & $\mathrm{N}$ & $\mathrm{Y}$ & $\mathrm{Y}$ & $\mathrm{Y}$ \\
\hline Reske et al. 2009 & $18 / 18$ & & & & $\mathrm{~N}$ & $\mathrm{~N}$ & \\
\hline
\end{tabular}

scz, Schizophrenia; con, controls $\mathrm{Y}$, identified as impaired in the study; $\mathrm{N}$, identified as unimpaired in the study.

certain emotions. In support of this, a recurrent theme in the literature has been that patients with schizophrenia have more difficulty in recognizing negative facial expressions than positive ones (Gaebel \& Wolwer, 1992; Archer et al. 1994; Bellack et al. 1996; Phillips et al. 1999; Edwards et al. 2001; Kohler et al. 2003; Bediou et al. 2005a; Van't Wout et al. 2007). Some of these studies have also argued that schizophrenia patients show selective impairment in the identification of fear and/or sadness (Gaebel \& Wolwer, 1992; Archer et al. 1994; Bellack et al. 1996). Nevertheless, perusal of recent studies that have reported performance of schizophrenia patients and controls on some or all of the six universal emotions described by Ekman \& Friesen (1976) reveals that most have documented deficits that generalized across the majority of emotions (see Table 1). It is also apparent that some studies have found no impairment for the negative emotions of fear, disgust and anger. Only one study (Hall et al. 2008) found evidence of a deficit affecting one specific emotion (fear).

A further way of indexing neuropsychological specificity of the schizophrenic facial emotion deficit would be to demonstrate that it is dissociated from performance on tasks requiring processing of nonemotional facial information. Neuropsychological models of face processing propose that facial perceptual information is first assembled into a 'structural encoding of the facial percept'. Thereafter, processing proceeds in separate parallel streams concerned with facial emotion, recognition of the person's identity and features such as judgement of age (Ellis \& Young, 1988); or alternatively facial expression and facial identity information is extracted differentially from a common representational system, resulting in a relative rather than an absolute dissociation between these two facial cues (Calder \& Young, 2005). Neuroimaging studies also support the existence of separate systems for the analysis of face invariant (e.g. identity) and variant (e.g. emotional expression) information in the superior temporal gyrus and lateral fusiform gyrus respectively (Haxby et al. 2000). Studies comparing the performance of schizophrenia patients on facial emotion processing tasks to that on other aspects of face processing have had inconclusive findings (Novic et al. 1984; Walker et al. 1984; Archer et al. 1992; Kerr \& Neale, 1993; Laws et al. 1996; Salem et al. 1996). However, two recent studies have reopened the debate, arguing for greater impairment on facial emotion tasks than on structural encoding of the facial percept (Kucharska-Pietura et al. 2005) and on judging age from faces (Schneider et al. 2006).

In this study, we attempted to address some of the unresolved issues surrounding the specificity of the 
facial emotion processing deficit in schizophrenia. First, to minimize the confounding effects of general intellectual impairment on performance, we selected patients who met a criterion for relative intellectual intactness. Second, we examined all six universally recognized emotions. Third, we included both a task requiring identification of emotions and one requiring subjects to determine the degree to which faces express emotions. Fourth, we included two tasks requiring processing of non-emotional facial information.

\section{Method}

\section{Participants}

The sample consisted of 22 patients with schizophrenia and 20 healthy participants. The patients with schizophrenia were in-patients $(n=3)$ and out-patients $(n=19)$ in a rehabilitation service. They were all on treatment with antipsychotic medication (atypical 20, typical 2) and were in a stable clinical state at the time of testing. They all met DSM-IV criteria for schizophrenia, based on a structured psychiatric interview (Present State Examination, 9th edition, PSE-9; Wing et al. 1974) and a review of case-notes. All patients had chronic illnesses with a mean duration of 15.65 (s.D. $=7.53$, range $4-31$ ) years.

The controls were healthy volunteers recruited by advertisement in the local community. Individuals were excluded if they reported a history of neurological illness, major psychiatric illness requiring treatment or hospitalization, or regular drug use. None of the subjects reported alcohol use beyond social drinking.

The study aimed to match patients and controls for age, sex and estimated IQ (pre-morbid IQ in the patients) using the revised National Adult Reading Test (NART-R; Nelson \& Willison, 1991). The schizophrenia patients were also required to show relatively preserved overall current intellectual function, defined as an IQ $\geqslant 85$ on the Wechsler Adult Intelligence Scale Revised (WAIS-R), that is within one standard deviation (1 S.D.) of the population average.

All subjects gave written informed consent prior to participating and the study was conducted with local health service ethics committee approval.

\section{Procedure}

The participants performed a series of computerized tasks designed to test different aspects of face processing. These included two tests of emotional face processing, a test of familiar face recognition and the Benton Facial Recognition Test (BFRT; Benton et al. 1994), a structural encoding task.

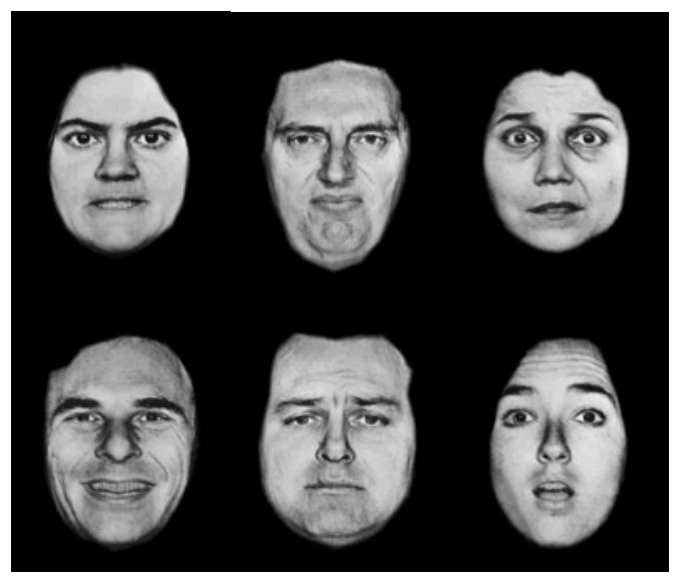

Fig. 1. Examples of the six different expressions at $50 \%$ intensity: above (left to right): anger, disgust, fear; below (left to right): happiness, sadness, surprise.

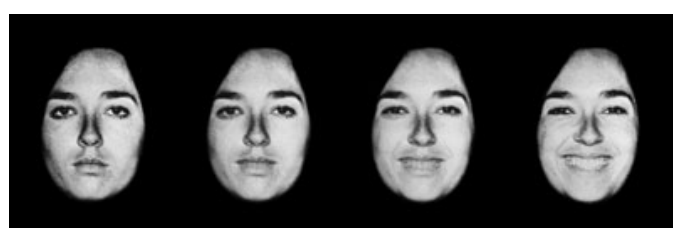

Fig. 2. Examples of emotion intensity stimuli: happiness at $0,26,52$ and $78 \%$.

\section{Judgement of facial emotion}

As recommended by Edwards et al. (2002), we used all of Ekman's six basic emotions in addition to neutral faces. The task consisted of 60 black-and-white pictures of people's faces, taken from the standard set of Ekman faces (Ekman \& Friesen, 1976). The pictures showed the six different basic emotions (anger, disgust, fear, happiness, sadness and surprise; see Fig. 1). To avoid the task being too easy, faces were presented showing $50 \%$ intensity of the emotion. Hairstyles and clothing were occluded from the images. Ten pictures of each facial expression in different people's faces were presented in random order. The subject had to select (using a mouse click) which emotion the person was showing from seven options, the above six emotions and neutral. Both accuracy and reaction time were recorded.

\section{Judgement of intensity of facial emotion}

This test used 96 black-and-white photographs of people's faces showing Ekman \& Friesen's (1976) six different basic emotions at four different degrees of intensity of the emotion: 0, 26, 52 and 78\% (for an example of happiness, see Fig. 2). Again, hairstyles 
Table 2. Characteristics of the sample

\begin{tabular}{lccl}
\hline & Control $(n=20)$ & Schizophrenia $(n=22)$ & Significance \\
\hline Age (years) & $36.10(10.12)$ & $39.4(13.17)$ & N.s. \\
Gender (F/M) & $6 / 14$ & $6 / 16$ & N.S. \\
NART-R IQ & $110.9(7.53)$ & $105.50(11.26)$ & $F=3.84, p=0.06$ \\
WAIS-R IQ & - & $96.05(10.08)$ & - \\
\hline
\end{tabular}

F, Female; M, male ; NART-R, National Adult Reading Test Revised ; WAIS-R,

Wechsler Adult Intelligence Scale Revised; N.S., not significant.

Values are mean (s.D.).

and clothing were occluded from the images. There were 16 pictures of each emotion in different faces, randomly distributed in terms of emotion and intensity. The subject was asked to judge the intensity of the emotion of the face that appeared on the screen by moving the mouse along a sliding scale from $0 \%$ to $100 \%$. In this task, there was no requirement to identify the emotion being shown.

\section{Famous people test}

This was shortened from a test developed by Bernard et al. (2004). Forty black-and-white pictures of wellknown people (worldwide and in the UK) were presented individually. The participants were asked to recall their names and to state in which area of life they were famous (e.g. actor, politician).

\section{BFRT (Benton et al. 1994)}

This test requires the subject to match a photograph of a person's face to one of six others. In the first part of the test (six items), the target face is identical to one of the six faces. In the remaining part of the test (16 items), the target face has to be matched with six faces that are shown in three-quarter profile, sometimes in different lighting conditions. Here, three of the six faces are of the same person as the target face. Subjects saw the target face at the top of the screen and the six other faces were displayed below it. The subjects were told to make as many choices as they wished for each item. Performance was scored across both components of the test.

\section{Data analysis}

All latency and proportion data were log and arcsine transformed respectively. Skewness and kurtosis statistics $\left(g_{1}\right.$ and $\left.g_{2}\right)$ were computed, as was the D'Agostino-Pearson omnibus test for normality (which uses both $g_{1}$ and $g_{2}$ as input to determine whether the distributions differed significantly from normality).

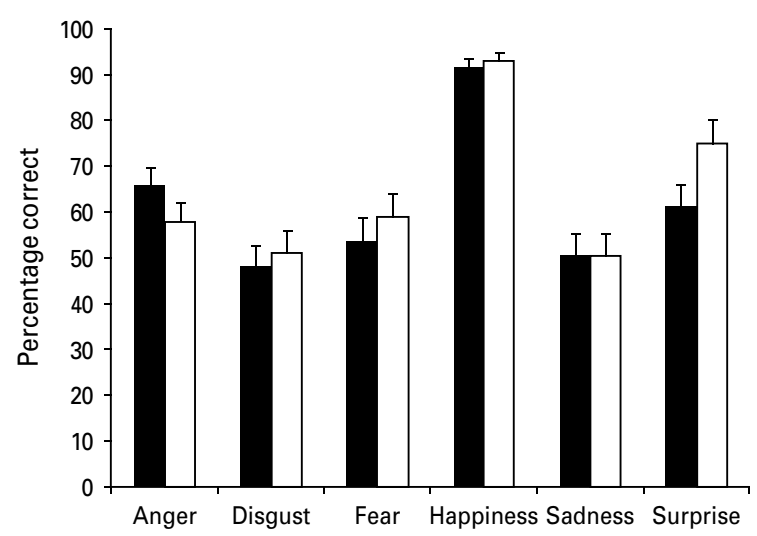

Fig. 3. Facial emotion judgement ( $\%$ correct) in schizophrenia patients ( $\square$ ) and healthy controls $(\square)$ task. Means adjusted for National Adult Reading Test (NART-R) IQ; error bars $=$ standard error.

\section{Results}

Demographic findings are shown in Table 2. The two groups did not differ in age and sex distribution. A trend-level difference in NART-estimated IQ emerged and so NART was included as a covariate in all analyses. Current WAIS-R IQ ranged from 86 to 130 in the schizophrenia patients. Mean Global Assessment Scale (GAS; Endicott et al. 1976) score in the patients was 38.43 (s.D. $=4.5$, range $27-50$ ), indicating moderate to severe levels of illness.

\section{Facial emotion processing}

Analysis was by means of an ANCOVA with emotion (six levels) as a repeated measure and group (two levels) as a between-subject factor. The GreenhouseGeisser adjustment was used to correct for violation of the assumption of sphericity for the repeatedmeasures factor.

\section{Judgement of emotion}

The performance of patients and controls is shown in Fig. 3. There was no main effect of emotion $[F=1.97$ 


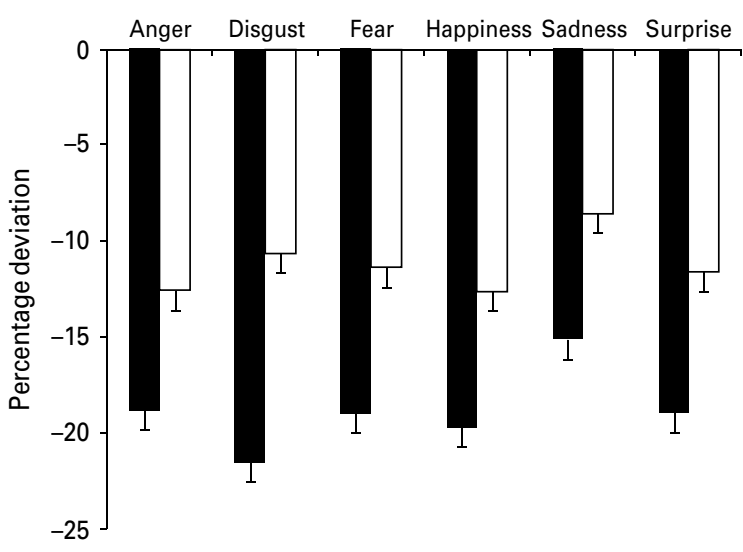

Fig. 4. Bias in judgement of intensity of facial emotion ( $\%$ deviation from correct, taking account of direction) by schizophrenia patients ( $\square$ ) and healthy controls $(\square)$. Means adjusted for National Adult Reading Test (NART) IQ; error bars $=$ standard error

$\left.(\mathrm{df}=4.03,157.0), \quad p=0.10, \eta_{\mathrm{p}}^{2}=0.05\right]$, no main effect of group $(F<1)$ and no interaction between group and emotion $\left[F=1.46(\mathrm{df}=4.03,157.0), p=0.22, \eta_{\mathrm{p}}^{2}=\right.$ 0.04]. Individual ANCOVAs for each emotion failed to find any significant difference: all $F<1$, except anger $[F=1.9(\mathrm{df}=1,39), \quad p=0.17]$ and surprise, which approached significance $[F=3.6 \quad(\mathrm{df}=1,39)$, $p=0.07]$.

Analysis of the latency data revealed a significant main effect for group $\left[F=9.6(\mathrm{df}=1,39), p=004, \eta_{\mathrm{p}}^{2}=\right.$ 0.20 ] but not for emotion $(F<1)$ or for the group $\times$ emotion interaction $(F<1)$. The schizophrenia patients were significantly slower than the controls when making emotion judgements across all six emotions.

\section{Judgement of intensity of emotion}

Accuracy of performance on this task was assessed by measuring deviation from the correct percentage, ignoring the direction of deviation (i.e. whether the subject over- or underestimated the intensity of the emotion). The schizophrenia patients performed significantly more poorly than the controls on all six facial expressions $[F=18.78 \quad(\mathrm{df}=1,35), \quad p<0.001$, $\left.\eta_{\mathrm{p}}^{2}=0.35\right]$ but there was no main effect for emotion $\left[F=1.22(\mathrm{df}=4.23,148.13), p=0.30, \eta_{\mathrm{p}}^{2}=0.03\right]$ and no group $\times$ emotion interaction $[F=1.3(\mathrm{df}=4.23,148.14)$, $\left.p=0.29, \eta_{\mathrm{p}}^{2}=0.03\right]$.

It is also possible to examine for bias to under- or overestimate the intensity of the emotion by reinstating the direction of the deviation (i.e. as a positive or negative sign). As shown in Fig. 4, the patients and the controls underestimated the intensity of emotion and this tendency was exaggerated in the schizophrenia patients. The group difference was significant $[F=10.6$ $\left.(\mathrm{df}=1,35), \quad p=0.003, \eta_{\mathrm{p}}^{2}=0.23\right]$. As before, neither the main effect for emotion nor the group $\times$ emotion interaction were significant (both $F<1$ ).

\section{Famous faces}

A one-way ANCOVA revealed that patients with schizophrenia named significantly fewer famous faces than the controls [mean $=23.46$ v. $28.54 ; F=4.30$ $\left.(\mathrm{df}=1,39), p=0.04, \eta_{\mathrm{p}}^{2}=0.10\right]$. We also used ANCOVA to examine the number of faces for which participants produced the occupation of the person; this difference was significant at trend level between patients and healthy controls $[$ mean $=29.68$ v. 34.90; $F=2.97$ $\left.(\mathrm{df}=1,39), p=0.093, \eta_{\mathrm{p}}^{2}=0.07\right]$.

\section{BFRT}

Data were missing for three controls and two patients on this test. Although the mean for patients with schizophrenia was lower than for the controls (mean = 32.44 v. 36.54), a one-way ANCOVA revealed no significant effect for group $[F=2.7(\mathrm{df}=1,34), p=0.11$, $\left.\eta_{\mathrm{p}}^{2}=0.07\right]$.

\section{Discussion}

In this study, a sample of relatively intellectually preserved patients with schizophrenia did not differ significantly from healthy controls in their ability to identify Ekman's six basic facial emotions. In fact, in the case of anger, their accuracy was even marginally better than the controls. It is true that the patients were slower than the controls; however, slowing of reaction time is a general feature of schizophrenia (Schatz, 1998) and so this finding cannot provide support for the existence of a specific emotion processing deficit. We did find that the patients consistently underestimated the intensity of facial emotions, although in this task there was no requirement to identify the emotion displayed. Finally, the patients and controls did not differ in the structural encoding of faces, but were significantly poorer at recognizing famous faces.

Our negative findings concerning identification of facial emotions run counter to the majority of published studies. They do not seem to be readily attributable to a lack of statistical power; our sample size of 22 patients and 20 controls is close to the median sample size of 24 for patients and controls in the recent studies shown in Table 1 . Nor does it seem likely that the task was too easy; we required participants to select the emotion from one of seven labels for each face presented. This is in contrast to 
several studies in which the schizophrenia patients only had to choose between two or three emotions (e.g. Gur et al. 2002; Bigelow et al. 2006; Tsoi et al. 2008; Derntl et al. 2009). Additionally, aside from happiness, no evidence of ceiling effects emerged in our data.

Alternatively, as we displayed emotions at 50\% intensity, it might be argued that our task was too difficult. This latter possibility is difficult to evaluate because most studies have not specified the intensity of emotion they used. However, it seems unlikely because (a) a study by Bediou et al. (2007) examining the recognition of four facial emotions morphed in $10 \%$ increments from $0 \%$ to $100 \%$ revealed significant differences between schizophrenia patients and controls from 30\% upwards; and (b) Kohler et al. (2003) found that schizophrenia patients displayed greater impairment than healthy controls when identifying lowerintensity than higher-intensity emotional expressions. Moreover, the range of percentage correct for our controls (49\% for sad through to $92 \%$ for happiness) recorded in our study is comparable with many other studies (e.g. Kohler et al. 2003; Bediou et al. 2005a,b; Kucharska-Pietura et al. 2005; Chambon et al. 2006; Schneider et al. 2006; Reske et al. 2009; Hofer et al. 2009).

Contrary to previous research (Gaebel \& Wolwer, 1992; Archer et al. 1994; Bellack et al. 1996; Phillips et al. 1999; Edwards et al. 2001; Kohler et al. 2003; Bediou et al. 2005a, b; Van't Wout et al. 2007), we found no evidence of impaired recognition for negative emotions such as fear, disgust and sadness. It is noteworthy, however, that in previous studies positive emotions have been confined largely to happiness, which is invariably the easiest of all face emotions to recognize, thus creating ceiling effects, or to surprise. The latter might also be important insofar as surprise was the only expression where we found that patients with schizophrenia showed a borderline trend to be impaired. Surprise has been less commonly examined than the other emotional expressions in schizophrenia (see Table 1); nevertheless, it has shown the greatest frequency of impairment in patients.

Why do our findings differ from the majority of other studies of facial emotion processing in schizophrenia? In contrast to all other studies, we adopted a strategy of testing intellectually preserved patients. As noted in the introduction, some authors (Archer et al. 1992; Kerr \& Neale, 1993; Salem et al. 1996) have argued that poor facial emotion recognition in schizophrenia could simply reflect generalized intellectual impairment, and this view has also been echoed in two recent critical reviews (Johnston et al. 2001; Edwards et al. 2002). It follows that, if steps were taken to reduce the effects of general intellectual impairment on specific test performance, the deficit in facial emotion processing might be partially or completely abolished. We did this, with results that were in line with predictions.

Although the intellectually preserved schizophrenia patients in our study showed no deficit in identifying different facial emotions, they were impaired on a task requiring estimation of the degree to which an emotion was present without identifying it. There would seem to be two possible interpretations of this finding. One is that there is a restricted form of facial emotion processing deficit in schizophrenia, albeit not the one that has preoccupied schizophrenia research in recent years, the inability to distinguish emotions from one another. Alternatively, because the intensity impairment occurred to much the same degree across all emotions and took the form of an exaggeration of the same tendency seen in the normal controls, it could be construed merely as an aspect of the general tendency to poor cognitive performance that characterizes schizophrenia. In support of this possibility, it can be noted that, although the patients in our study were selected on the basis of showing preserved general intellectual function, this was relative rather than absolute; they still showed a decline in IQ of nearly 10 points from their NART-estimated pre-morbid level. Nevertheless, at present it does not seem possible to choose between these two hypotheses.

Although, as noted in the introduction, studies comparing the performance of schizophrenia patients on facial emotion processing tasks to other aspects of face processing have produced mixed findings (Novic et al. 1984; Walker et al. 1984; Archer et al. 1992; Kerr \& Neale, 1993; Laws et al. 1996; Salem et al. 1996), two recent studies have reported greater impairment on facial emotion tasks than on structural encoding of the facial percept (Kucharska-Pietura et al. 2005) and on judging age from faces (Schneider et al. 2006). Kucharska-Pietura et al. (2005) found that 100 patients with schizophrenia (50 chronically ill and 50 in the early stages of illness) showed impairment on both an emotional face processing task and the BFRT. However, the effect size was larger in the facial emotion task, and the difference remained significant when performance on the BFRT was entered as a covariate in the analysis. However, it should be noted that the facial emotion task that Kucharska-Pietura et al. (2005) used consisted of a set of faces showing nine 'fundamental emotions' rather than the six basic emotions used by Ekman \& Friesen (1976); these included interest/excitement, contempt and shame/ humiliation. It is therefore possible that their task had a greater theory of mind 'load' than ours; in other words, the subjects had to make inferences about the 
mental state of the people pictured rather than just detect facial emotional signals (Brune, 2005a). Impairment on a wide range of theory of mind tasks has been documented in schizophrenia, with effect sizes that are greater than can be accounted for by general intellectual impairment (Brune, 2005b; Sprong et al. 2007). Indeed, Kucharska-Pietura et al. (2005) found that interest and shame produced the largest effects, especially for the chronically ill patients.

Schneider et al. (2006) found that 20 schizophrenia patients showed significantly greater impairment on a task requiring identification of four emotions, happiness, sadness, anger and fear, than on a task requiring them to judge the age of the same faces. However, other studies, including those by the same group (Schneider et al. 1995; Kohler et al. 2000; Derntl et al. 2009), have found that schizophrenia patients were impaired on both facial emotion identification and age discrimination with no or less obvious differences between the two.

Although our intellectually well-preserved schizophrenia patients failed to show an impairment of emotional face identification, they did show impairment on a task requiring identification of familiar faces. The combination of non-significant impairment on the BFRT with impaired recognition of familiar faces suggests that there could be a problem in facial identity processing in schizophrenia, which is carried out independently (Ellis \& Young, 1988) or partially independently (Calder \& Young, 2005) of facial emotion processing. Laws et al. (1996) reported similar findings in a study using the single case study design: 2/10 intellectually relatively well-preserved schizophrenia patients failed the BFRT; $3 / 10$ failed tasks requiring judgement of age from faces; and 3/10 failed judgement of facial expression. By contrast, more than twice as many, $7 / 10$, failed a test of famous face recognition. However, neither the study of Laws et al. (1996) nor the present study used a task that required the subjects to judge face familiarity without providing identifying information about the person. In the framework of the Bruce \& Young model of face processing (Ellis \& Young, 1988), therefore, it is not possible to distinguish between a problem with facial identity processing per se (i.e. impairment at the level of the so-called facial recognition units) and a problem with retrieval of semantic information about the familiar person (i.e. impairment in 'personal identity nodes'). Whatever the location of this deficit, however, it fits broadly with the finding that schizophrenia patients show a deficit in visual object processing that affects object recognition units and semantic memory (Gabrovska et al. 2003), and also with other lines of evidence pointing to semantic memory impairment in schizophrenia (McKenna et al. 2002).

\section{Acknowledgements}

This work was supported by the Instituto de Salud Carlos III, Centro de Investigación en Red de Salud Mental, CIBERSAM, Spain.

\section{Declaration of Interest}

None.

\section{References}

Archer J, Hay DC, Young AW (1992). Face processing in psychiatric conditions. British Journal of Psychiatry 31, 45-61.

Archer J, Hay DC, Young AW (1994). Movement, face processing and schizophrenia: evidence of a differential deficit in expression analysis. British Journal of Clinical Psychology 33, 517-528.

Bediou B, Asri F, Brunelin J, Krolak-Salmon P, D'Amato T, Saoud M, Tazi I (2007). Emotion recognition and genetic vulnerability to schizophrenia. British Journal of Psychiatry 191, 126-130.

Bediou B, Franck N, Saoud M, Baudouin JY, Tiberghien G, Dalery J, d'Amato T (2005a). Effects of emotion and identity on facial affect processing in schizophrenia. Psychiatry Research 133, 149-157.

Bediou B, Krolak-Salmon P, Saoud M, Henaff MA, Burt M, Dalery J, D'Amato T (2005b). Facial expression and sex recognition in schizophrenia and depression. Canadian Journal of Psychiatry 50, 525-533.

Bellack AS, Blanchard JJ, Mueser KT (1996). Cue availability and affect perception in schizophrenia. Schizophrenia Bulletin 22, 535-544.

Benton AL, Sivan AB, Hamsher KD (1994). Contributions to Neuropsychological Assessment: A Clinical Manual. Oxford University Press: Oxford.

Bernard FA, Bullmore ET, Graham KS, Thompson SA, Hodges JR, Fletcher PC (2004). The hippocampal region is involved in successful recognition of both remote and recent famous faces. Neuroimage 22, 1704-1714.

Bigelow NO, Paradiso S, Adolphs R, Moser DJ, Arndt S, Heberlein A, Nopoulos P, Andreasen NC (2006).

Perception of socially relevant stimuli in schizophrenia. Schizophrenia Research 83, 257-267.

Brune M (2005a). Emotion recognition, 'theory of mind,' and social behavior in schizophrenia. Psychiatry Research 133, 135-147.

Brune M (2005b). 'Theory of mind' in schizophrenia: a review of the literature. Schizophrenia Bulletin 31, 21-42.

Calder AJ, Young AW (2005). Understanding the recognition of facial identity and facial expression. Nature Reviews. Neuroscience 6, 641-651.

Chambon V, Baudouin JY, Frank N (2006). The role of configural information in facial emotion recognition in schizophrenia. Neuropsychologia 44, 2437-2444.

Chapman LJ, Chapman JP (1973). Disordered Thought in Schizophrenia. Appleton-Century-Crofts: New York. 
Derntl B, Finkelmeyer A, Toygar TK, Hulsmann A, Schneider F, Falkenberg DI, Habel U (2009). Generalized deficit in all core components of empathy in schizophrenia. Schizophrenia Research 108, 197-206.

Edwards J, Jackson HJ, Pattison PE (2002). Emotion recognition via facial expression and affective prosody in schizophrenia: a methodological review. Clinical Psychology Review 22, 789-832.

Edwards J, Pattison PE, Jackson HJ, Wales RJ (2001). Facial affect and affective prosody recognition in first-episode schizophrenia. Schizophrenia Research 48, 235-253.

Ekman P, Friesen W (1976). Pictures of Facial Affect. Consulting Psychologists Press: Palo Alto.

Ellis AW, Young AW (1988). Human Cognitive Neuropsychology. Erlbaum: Hove.

Endicott J, Spitzer RL, Fleiss JL, Cohen J (1976). The global assessment scale. A procedure for measuring overall severity of psychiatric disturbance. Archives of General Psychiatry 33, 766-771.

Gabrovska VS, Laws KR, Sinclair J, McKenna PJ (2003). Visual object processing in schizophrenia: evidence for an associative agnosic deficit. Schizophrenia Research 59, 277-286.

Gaebel W, Wolwer W (1992). Facial expression and emotional face recognition in schizophrenia and depression. European Archives of Psychiatry and Clinical Neuroscience 242, 46-52.

Gur RE, McGrath C, Chan RM, Schroeder L, Turner T, Turetsky BI, Kohler C, Alsop D, Maldjian J, Ragland JD, Gur RC (2002). An fMRI study of facial emotion processing in patients with schizophrenia. American Journal of Psychiatry 159, 1992-1999.

Hall J, Whalley HC, McKirdy JW, Romaniuk L, McGonigle D, McIntosh AM, Baig BJ, Gounto una VE, Job DE, Donaldson DI, Sprengelmeyer R, Young AW, Johnstone EC, Lawrie SM (2008). Overactivation of fear systems to neutral faces in schizophrenia. Biological Psychiatry 64 70-73.

Haxby JV, Hoffman EA, Gobbini MI (2000). The distributed human neural system for face perception. Trends in Cognitive Sciences 4, 223-233.

Hofer A, Benecke C, Edlinger M, Huber R, Kemmler G, Rettenbacher MA, Schleich G, Fleischhacker WW (2009). Facial emotion recognition and its relationship to symptomatic, subjective, and functional outcomes in outpatients with chronic schizophrenia. European Psychiatry 24, 27-32.

Johnston PJ, Enticott PG, Mayes AK, Hoy KE, Herring SE, Fitzgerald PB (2008). Symptom correlates of static and dynamic facial affect processing in schizophrenia: evidence of a double dissociation? Schizophrenia Bulletin. Published online: 26 October 2008. doi:10.1093/schbul/ sbn136.

Johnston PJ, Katsikitis M, Carr VJ (2001). A generalised deficit can account for problems in facial emotion recognition in schizophrenia. Biological Psychology 58, 203-227.

Kerr SL, Neale JM (1993). Emotion perception in schizophrenia: specific deficit or further evidence of generalized poor performance? Journal of Abnormal Psychology 102, 312-318.

Kohler CG, Bilker W, Hagendoorn M, Gur RE, Gur RC (2000). Emotion recognition deficit in schizophrenia: association with symptomatology and cognition. Biological Psychiatry 48, 127-136.

Kohler CG, Turner TH, Bilker WB, Brensinger CM, Siegel SJ, Kanes SJ, Gur RE, Gur RC (2003). Facial emotion recognition in schizophrenia: intensity effects and error pattern. American Journal of Psychiatry 160, 1768-1774.

Kohler CG, Walker JB, Martin EA, Healey KM, Moberg PJ (2009). Facial emotion perception in schizophrenia : a meta-analytic review. Schizophrenia Bulletin. Published online: 27 March 2009. doi:10.1093/ schbul/sbn192.

Kucharska-Pietura K, David AS, Masiak M, Phillips ML (2005). Perception of facial and vocal affect by people with schizophrenia in early and late stages of illness. British Journal of Psychiatry 187, 523-528.

Laws K, McKenna PJ, McCarthy RA (1996). Reconsidering the gospel according to group studies: a neuropsychological case study approach to schizophrenia. Cognitive Neuropsychiatry 1, 319-343.

Mandal MK, Pandey R, Prasad AB (1998). Facial expressions of emotions and schizophrenia: a review. Schizophrenia Bulletin 24, 399-412.

Marwick K, Hall J (2008). Social cognition in schizophrenia: a review of face processing. British Medical Bulletin 88, 43-58.

McKenna PJ (2007). Schizophrenia and Related Syndromes, 2nd edn. Routledge: Hove.

McKenna PJ, Ornstein T, Baddeley AD (2002). Schizophrenia. In Handbook of Memory Disorders (ed. A. D. Baddeley, B. A. Wilson and M. Kopelman), pp. 413-435. Wiley: Chichester.

Namiki C, Hirao K, Yamada M, Hanakawa T, Fukuyama H, Hayashi T, Murai T (2007). Impaired facial emotion recognition and reduced amygdalar volume in schizophrenia. Psychiatry Research 156, 23-32.

Nelson HE, Willison JR (1991). The Revised National Adult Reading Test: Test Manual. NFER-Nelson: Windsor, Berks.

Novic J, Luchins DJ, Perline R (1984). Facial affect recognition in schizophrenia. Is there a differential deficit? British Journal of Psychiatry 144, 533-537.

Phillips ML, Williams L, Senior C, Bullmore ET, Brammer MJ, Andrew C, Williams SC, David AS (1999). A differential neural response to threatening and non-threatening negative facial expressions in paranoid and non-paranoid schizophrenics. Psychiatry Research 92, 11-31.

Pinkham AE, Penn DL, Perkins DO, Lieberman J (2003). Implications for the neural basis of social cognition for the study of schizophrenia. American Journal of Psychiatry 160, 815-824.

Reichenberg A, Harvey PD (2007). Neuropsychological impairments in schizophrenia: integration of performance-based and brain imaging findings. Psychological Bulletin 133, 833-858. 
Reske M, Habel U, Kellermann T, Backes V, Jon Shah N, von Wilmsdorff M, Gaebel W, Zilles K, Schneider F (2009). Differential brain activation during facial emotion discrimination in first-episode schizophrenia. Journal of Psychiatric Research 43, 592-599.

Sachs G, Steger-Wuchse D, Kryspin-Exner I, Gur RC, Katschnig H (2004). Facial recognition deficits and cognition in schizophrenia. Schizophrenia Research 68, 27-35.

Salem JE, Kring AM, Kerr SL (1996). More evidence for generalized poor performance in facial emotion perception in schizophrenia. Journal of Abnormal Psychology 105, 480-483.

Schatz J (1998). Cognitive processing efficiency in schizophrenia: generalized vs domain specific deficits. Schizophrenia Research 30, 41-49.

Schneider F, Gur RC, Gur RE, Shtasel DL (1995). Emotional processing in schizophrenia: neurobehavioral probes in relation to psychopathology. Schizophrenia Research 17, 67-75.

Schneider F, Gur RC, Koch K, Backes V, Amunts K, Shah NJ, Bilker W, Gur RE, Habel U (2006). Impairment in the specificity of emotion processing in schizophrenia.

American Journal of Psychiatry 163, 442-447.

Silver H, Shlomo N, Turner T, Gur RC (2002). Perception of happy and sad facial expressions in chronic schizophrenia : evidence for two evaluative systems. Schizophrenia Research 55, 171-177.
Sprong M, Schothorst P, Vos E, Hox J, van Engeland H (2007). Theory of mind in schizophrenia: meta-analysis. British Journal of Psychiatry 191, 5-13.

Tsoi DT, Lee KH, Khokhar WA, Mir NU, Swalli JS, Gee KA, Pluck G, Woodruff PW (2008). Is facial emotion recognition impairment in schizophrenia identical for different emotions? A signal detection analysis. Schizophrenia Research 99, 263-269.

Turetsky BI, Kohler CG, Indersmitten T, Bhati MT, Charbonnier D, Gur RC (2007). Facial emotion recognition in schizophrenia: when and why does it go awry? Schizophrenia Research 94, 253-263.

Van't Wout M, van Dijke A, Aleman A, Kessels RP, Pijpers W, Kahn RS (2007). Fearful faces in schizophrenia: the relationship between patient characteristics and facial affect recognition. Journal of Nervous and Mental Disease 195, 758-764.

Walker E, McGuire M, Bettes B (1984). Recognition and identification of facial stimuli by schizophrenics and patients with affective disorders. British Journal of Clinical Psychology 23, 37-44.

Wing JK, Cooper JE, Sartorius N (1974). The Measurement and Classification of Psychiatric Symptoms. Cambridge University Press: Cambridge.

Wynn JK, Lee J, Horan WP, Green MF (2008). Using event related potentials to explore stages of facial affect recognition deficits in schizophrenia. Schizophrenia Bulletin 34, 679-687. 